\title{
RISK ASSESSMENT KECELAKAAN KERJA PEMASANGAN BETON PRACETAK PADA PROYEK PEMBANGUNAN APARTEMEN DI SURABAYA
}

\author{
ACCIDENT WORK RISK ASSESSMENT ON PRECAST CONCRETE \\ INSTALLATION AT APARTMENT PROJECT IN SURABAYA
}

\author{
Reko Triyono, Noeroel Widajati \\ Departemen Keselamatan dan Kesehatan Kerja \\ Fakultas Kesehatan Masyarakat Universitas Airlangga \\ E-mail: rekotriyono12@gmail.com
}

\begin{abstract}
Installation of precast concrete in construction of multi-storey buildings at risk of workplace accidents due to be carried out on the altitude. Installation of precast concrete must also use heavy equipment, because of the weight of the material to be install. Accidents on the installation of precast concrete can be very fatal and cause of death. Risk assessment is an attempt to calculating risk arising from hazards, take into account the adequacy of any existing controls, and deciding whether or not the risk is acceptable. The purpose of this research is to studies and perform risk assessment level on precast concrete installation at apartment project in Surabaya with hazard, risk, risk control, and residual risk observation. Primary data were collected through interview and observation. Object of this research is installation proses of precast concrete wall at Puncak Bukit Golf Apartment project by PT. Wijaya Karya Bangunan Gedung in Surabaya. The data was analyzed descriptively using table and narration. Results showed that hazard identify in precast concrete installation at apartment project in Surabaya include fall from height, squeezed, fallen object, struck by precast concrete, crush by precast concrete, and electro shock. Risk assessment has obtained 21 hazards. Risk control with was done: installing safety net for falling objects, safety induction, work instruction, wear PPE, and wear fall protection. The result of risk assessment showed 19\% risk are high risk, $38 \%$ with moderate risk category, and $43 \%$ with low risk category.
\end{abstract}

Keywords: risk assessment, precast concrete installing

\begin{abstract}
ABSTRAK
Pemasangan beton pracetak pada pembangunan gedung bertingkat berisiko terhadap kecelakaan kerja karena harus dilakukan di atas ketinggian. Pemasangan beton pracetak juga harus menggunakan alat berat, karena beratnya material yang akan dipasang. Kecelakaan pada pemasangan beton pracetak bisa sangat fatal hingga menyebabkan kematian. Risk assessment merupakan upaya untuk menghitung besar risiko yang timbul dari suatu bahaya dengan memperhatikan kecukupan pengendalian yang dimiliki dan menentukan apakah risiko tersebut dapat diterima atau tidak. Tujuan dari penelitian ini adalah mempelajari dan melakukan risk assessment pada proses pemasangan beton pracetak pada proyek pembangunan apartemen di Surabaya dengan melihat aspek bahaya, risiko, pengendalian risiko, dan risiko sisa. Data primer dikumpulkan dengan cara wawancara dan observasi. Objek penelitian adalah proses pemasangan dinding beton pracetak Proyek Pembangunan Apartemen Puncak Bukit Golf PT. Wijaya Karya Bangunan Gedung. Data yang diperoleh kemudian diidentifikasi secara deskriptif dengan menggunakan tabel dan narasi. Hasil penelitian menunjukkan bahwa bahaya yang teridentifikasi pada pekerjaan pemasangan dinding beton pracetak pada proyek pembangunan apartemen di Surabaya meliputi terjatuh dari ketinggian, terjepit, material terjatuh, tertimpa, terbentur, dan tersengat aliran listrik. Penilaian risiko menghasilkan 21 potensi risiko. Pengendalian risiko yang dilakukan yaitu: memasang jaring pengamanan, safety induction, work instruction, APD, fall protection. Hasil penilaian risiko menunjukkan adanya $19 \%$ risiko dengan kategori tinggi, $38 \%$ risiko kategori sedang, dan $43 \%$ risiko kategori rendah.
\end{abstract}

Kata kunci: risk assessment, pemasangan beton pracetak

\section{PENDAHULUAN}

Pada tahun 2009 data Jamsostek menunjukkan 96.314 kasus kecelakaan kerja terjadi di Indonesia dan meningkat menjadi 98.711 kasus kecelakaan kerja pada tahun 2010. Data Depnakertrans menunjukkan bahwa tingkat kecelakaan kerja terbesar di Indonesia adalah sektor konstruksi. Kecelakaan pada sektor konstruksi menyumbang 32\% dari seluruh kecelakaan kerja (Ridwan, 2010). 
Kebutuhan akan sesuatu yang efisien secara waktu dan efektif dalam menghasilkan karya, namun tidak mengurangi kualitasnya belakangan sangat diperlukan. Sistem pengecoran beton pracetak dipilih oleh para pelaku konstruksi karena memiliki berbagai keunggulan, seperti: efisiensi waktu, penghematan anggaran keuangan, dan terjaganya kualitas (Tjitrosoma, 2012).

Menurut Harianto (2014) salah satu kegiatan di sektor konstruksi dengan potensi bahaya tinggi adalah pemasangan material precast atau beton pracetak dengan risiko tertinggi tertimpa. Pemasangan beton pracetak juga mempunyai risiko kecelakaan diantaranya ialah terjatuh, terbentur, dan terjepit. Akibatnya yaitu kerugian berupa risiko kecelakaan kerja pada tenaga kerja operasional, kerusakan material, molornya pengerjaan proyek, menurunnya pendapatan perusahaan, dan pengeluaran meningkat untuk biaya asuransi.

Perusahaan perlu melakukan tindakan untuk meminimalisir pengeluaran akibat terjadinya kecelakaan kerja. Salah satunya ialah manajemen risiko pekerjaan pemasangan beton pracetak. Manajemen risiko terdapat tahapan yang diantaranya ialah analisa tingkat risiko yang muncul, mempertimbangkan dan melakukan evaluasi atau tidak sumber bahaya dapat dikendalikan secara memadai, dan mengambil langkah-langkah yang tepat agar tidak ada satu orang pun kecelakaan dan permasalahan kesehatan, serta tidak ada kerusakan pada material dan lingkungan. Manajemen risiko tidak dapat lepas dari risk assessment.

Tujuan dari penelitian ini adalah melihat seberapa besar risiko kecelakaan kerja pemasangan beton pracetak pada proyek pembangunan apartemen dengan melakukan identifikasi bahaya, menilai potensi risiko, menganalisis upaya pengendalian munculnya potensi bahaya, dan menilai risiko sisa.

\section{METODE}

Penelitian ini merupakan penelitian observasional deskriptif dan menggunakan total sampling dengan jumlah responden 8 orang. Objek penelitian yaitu pekerjaan pemasang dinding beton pracetak (precast concrete) bangunan Sektor 1 Proyek Apartemen Puncak Bukit Golf Surabaya PT. Wijaya Karya Bangunan Gedung. Penelitian dilakukan pada Maret-April 2014.
Data primer didapatkan melalui hasil observasi dan wawancara. Observasi dilakukan dengan pengamatan langsung keadaan di tempat kerja mengenai proses pemasangan dinding beton pracetak yang dinilai berdasarkan identifikasi bahaya, penilaian risiko, penilaian pengendalian yang sudah dilakukan oleh perusahaan, dan penilaian risiko sisa. Wawancara dilakukan pada manajer K3, safety officer, operator tower crane, dan rigger. Data sekunder yang menunjang penelitian meliputi working instruction pemasangan beton pracetak, Standard Operational Procedure (SOP), dan Hazard Identification and Risk Assessment.

Tahapan awal penelitian adalah identifikasi bahaya dan analisis penilaian risiko yang dapat terjadi berdasarkan likelihood (kemungkinan) dan severity (keparahan) yang ditimbulkan atau disebut risiko murni. Hasil analisis diolah dengan menggunakan matriks risiko.

Penilaian pengendalian risiko yang telah dilakukan perusahaan terhadap pekerjaan pemasangan dinding beton pracetak mengacu pada pedoman pengendalian dari PT. Freeport Indonesia pada tabel 1 .

Berdasarkan penilaian pengendalian yang ada maka dapat dihitung besaran risiko sisa dengan rumus:

$$
\left(\frac{100 \% \text { - \% Pengendalian }}{100 \%}\right) \times \text { Risiko Murni }
$$

Tabel 1. Matriks Risiko

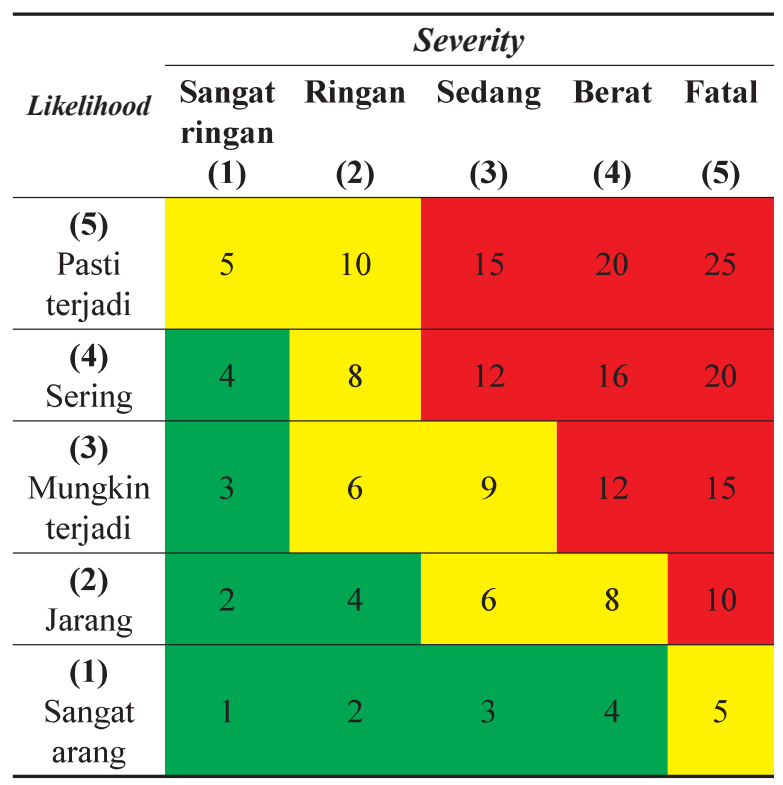

Sumber: Suardi, R. 2007 
Tabel 2. Pedoman Penilaian Pengendalian Risiko

\begin{tabular}{|c|c|c|}
\hline Nilai & Kategori & Deskripsi \\
\hline $100 \%$ & Istimewa & $\begin{array}{l}\text { Persyaratan yang lengkap dati kontrol yang ada dipenuhi dan ditaati dan tidak ada } \\
\text { keraguan bahwa persyaratan tersebut secara penuh diimplementasikan dan berfungsi. }\end{array}$ \\
\hline $90 \%$ & Sangat baik & Kontrol yang ada diimplementasikan dan berfungsi tetapi masih perlu ditingkatkan. \\
\hline $75 \%$ & $\begin{array}{l}\text { Diimplementasikan } \\
\text { dengan baik }\end{array}$ & $\begin{array}{l}\text { Kontrol yang ada diimplementasikan dan berfungsi, tetapi masih ada celah yang jelas } \\
\text { yang harus diperbaiki. }\end{array}$ \\
\hline $65 \%$ & Diimplementasikan & $\begin{array}{l}\text { Persyaratan kontrol yang ada diimplementasikan cukup baik, tetapi masih } \\
\text { memerlukan tindakan spesifik dan terfokus untuk memenuhi persyaratan. }\end{array}$ \\
\hline $50 \%$ & $\begin{array}{l}\text { Diimplementasikan } \\
\text { sebagian }\end{array}$ & $\begin{array}{l}\text { Persyaratan kontrol yang ada telah diimplementasikan sampai taraf tertentu, } \\
\text { memerlukan tindakan-tindakan spesifik untuk direncanakan dan diimplementasikan. }\end{array}$ \\
\hline $40 \%$ & $\begin{array}{l}\text { Diimplementasikan } \\
\text { kutang dari } 50 \%\end{array}$ & $\begin{array}{l}\text { Walaupun suatu tindakan dilakukan untuk memenuhi persyaratan suatu item ada } \\
\text { celah-celah (gaps) yang jelas dan ada kemungkinan kesalahpahaman terhadap } \\
\text { beberapa tindakan spesifik yang masih perlu diambil agar bisa secara semestinya } \\
\text { mengimplementasikan kontrol yang ada. }\end{array}$ \\
\hline $25 \%$ & Implementasi lemah & $\begin{array}{l}\text { Tidak ada tindakan riil yang telah diambil untuk mengimplementasikan } \\
\text { persyaratan. Jelas bahwa hal tertentu dari persyaratan tidak dipahami. Intervensi } \\
\text { spesifik harus diambil untuk memastikan bahwa kemajuan dibuat untuk } \\
\text { mengimplementasikan persyaratan. }\end{array}$ \\
\hline $15 \%$ & Ada pengertian & $\begin{array}{l}\text { Ada pengertian bahwa tindakan harus diambil tetapi hingga tanggal ini tidak ada } \\
\text { sesuatu yang telah dilakukan untuk mengimplementasikan persyaratan kontrol } \\
\text { yang ada. }\end{array}$ \\
\hline $0 \%$ & $\begin{array}{l}\text { Tidak } \\
\text { diimplementasikan }\end{array}$ & $\begin{array}{l}\text { Tidak ada yang sudah dilakukan sampai dengan tanggal ini untuk } \\
\text { mengimplementasikan persyaratan kontrol yang ada. Tidak ada pertimbangan } \\
\text { implementasi dalam waktu dekat. Pengertian tentang persyaratan mungkin ada, tetapi } \\
\text { tidak ada tindakan spesifik untuk memenuhinya. }\end{array}$ \\
\hline
\end{tabular}

Sumber: PT. Freeport Indonesia, 2008

\section{HASIL}

\section{Identifikasi Potensi Bahaya}

Tahapan pekerjaan pemasangan chain block pada tembok memiliki potensi bahaya bagian tubuh terjepit dan terjatuh dari ketinggian karena kolom tidak jauh dari tepi bangunan dan sebagian dinding tidak ada pagar pelindung (guard rails) serta pekerja tidak dilengkapi tali-temali pengaman.

Potensi bahaya pada pekerjaan pemasangan sling tower crane pada lift hook beton pracetak adalah bagian tubuh terjepit seperti tangan karena pekerja atau rigger tidak berhati-hati, tidak fokus dalam bekerja, kesalahan koordinasi dengan operator tower crane, dan tidak menggunakan alat pelindung diri (APD) berupa sarung tangan dari kulit serta sepatu safety atau steel box toe.

Pekerja pemasang atau rigger tertimpa sling atau beton pracetak saat erection berlangsung bisa dikarenakan tidak benarnya pekerja dalam memasang hook tower crane ataupun putusnya sling tower crane, serta pekerja pemasang tertabrak sling atau beton pracetak karena kesalahan dalam koordinasi antara pekerja pemasang sling tower crane pada hook beton pracetak dengan operator tower crane yang juga bias dikarenakan pengaruh cuaca dan lingkungan seperti hujan dan angin.

Tahapan pekerjaan erection beton pracetak mempunyai potensi bahaya, seperti: material terjatuh, tertabrak beton pracetak, beton pracetak terjatuh, pekerja tertimpa, dan terjatuh dari ketinggian. Pada tahapan pekerjaan erection adanya alat komunikasi berupa handy talky sangat berperan penting, karena alat ini merupakan pendukung utama sistem komunikasi antara rigger dengan operator tower crane. Mengingat pentingnya peran handy talky maka seharusnya handy talky yang digunakan rigger diikatkan atau digantungkan pada bagian tubuh sehingga mencegah agar tidak jatuh.

Tahapan pekerjaan pemindahan beton pracetak dari sling tower crane ke chain block pada tembok mempunyai potensi bahaya: bagian tubuh terjepit karena tidak memakai APD, terbentur, terjatuh dari ketinggian, beton pracetak terjatuh.

Tahap pekerjaan pengelasan beton pracetak mempunyai beberapa potensi bahaya, diantaranya 
Tabel 3. Identifikasi Potensi Bahaya

\begin{tabular}{|c|c|}
\hline \multicolumn{2}{|c|}{ Analisis Keselamatan Kerja } \\
\hline 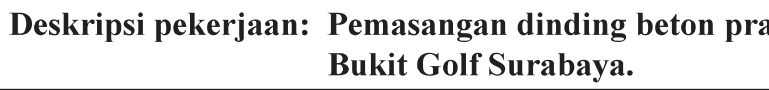 & tak bangunan Sektor 1 Gedung Apartemen Puncak \\
\hline Tahap Pekerjaan & Potensi Bahaya \\
\hline Pemasangan chain block pada kolom bangunan & $\begin{array}{l}\text { 1. Terjepit } \\
\text { 2. Terjatuh dari ketinggian }\end{array}$ \\
\hline Pemasangan sling tower crane pada lift hook beton pracetak & $\begin{array}{l}\text { 1. Terjepit } \\
\text { 2. Tertimpa } \\
\text { 3. Tertabrak sling/beton pracetak }\end{array}$ \\
\hline Erection beton pracetak & $\begin{array}{l}\text { 1. Beton pracetak terjatuh } \\
\text { 2. Tertabrak sling/beton pracetak } \\
\text { 3. Terjatuh dari ketinggian }\end{array}$ \\
\hline $\begin{array}{l}\text { Pemindahan beton pracetak dari sling tower crane ke } \\
\text { sling chain block }\end{array}$ & $\begin{array}{l}\text { 1. Terjepit } \\
\text { 2. Terbentur } \\
\text { 3. Terjatuh dari ketinggian } \\
\text { 4. Beton pracetak terjatuh }\end{array}$ \\
\hline Pengelasan beton pracetak & $\begin{array}{l}\text { 1. Las terjatuh } \\
\text { 2. Material terjatuh } \\
\text { 3. Terjatuh dari ketinggian } \\
\text { 4. Tersengat aliran listrik } \\
\text { 5. Gangguan penglihatan } \\
\text { 6. Bagian tubuh terkena percikan las }\end{array}$ \\
\hline Pelepasan chain block & $\begin{array}{l}\text { 1. Terjepit } \\
\text { 2. Terjatuh dari ketinggian } \\
\text { 3. Material terjatuh }\end{array}$ \\
\hline
\end{tabular}

adalah: las terjatuh, material terjatuh, terjatuh dari ketinggian, tersengat aliran listrik, gangguan penglihatan, dan bagian tubuh terkena percikan las.

Pekerjaan pelepasan sling pengikat beton pracetak akan menimbulkan tiga potensi bahaya yang meliputi potensi terjepit, terjatuh dari ketinggian, dan beton pracetak terjatuh.

Hasil identifikasi risiko bahaya pada pekerjaan pemasangan dinding beton pracetak Proyek Pembangunan Apartemen Puncak Bukit Surabaya ada beberapa risiko bahaya diantaranya ialah: risiko terjatuh dari ketinggian dengan jumlah 5 potensi, terjepit dengan 4 potensi, beton pracetak terjatuh dengan 3 potensi, tertabrak sling/beton pracetak dengan 2 potensi, 1 potensi tertimpa, 1 potensi tersengat aliran listrik, 1 potensi terkena percikan las, 1 potensi terbentur, 1 potensi las terjatuh, 1 potensi gangguan penglihatan, dan 1 potensi material terjatuh.

Dari tabel 4 maka diketahui bahwa potensi bahaya yang paling banyak teridentifikasi dari pekerjaan pemasangan beton pracetak dinding bangunan apartemen ialah terjatuh dari ketinggian dengan jumlah lima dan diikuti terjepit dengan empat jumlah potensi bahaya, beton pracetak terjatuh tiga potensi bahaya, tertabrak sling/beton pracetak dua, serta tertimpa, tersengat aliran listrik, terkena percikan las, terbentur, las terjatuh, gangguan penglihatan, serta material terjatuh dengan masingmasing satu.

Kategori risiko dari identifikasi potensi bahaya awal pada pekerjaan pemasangan beton pracetak dinding bangunan Proyek Pembangunan Apartemen Puncak Bukit Golf adalah 5\% risiko rendah, 19\% risiko sedang, dan $64 \%$ risiko tinggi.

\section{Pengendalian Risiko}

Untuk mengurangi potensi bahaya yang bisa menyebabkan kecelakaan maka perusahaan melakukan pengendalian risiko dalam bentuk pengendalian sebagai berikut: eliminasi, substitusi, pengendalian teknis, pengendalian administratif, dan penggunaan alat pelindung diri (APD). Eliminasi adalah teknik pengendalian dengan menghilangkan sumber bahaya. Dalam pengendalian risiko pada pekerjaan pemasangan 
Tabel 4. Penilaian Risiko

\begin{tabular}{|c|c|c|c|c|c|}
\hline \multicolumn{6}{|c|}{ Analisis Keselamatan Kerja } \\
\hline \multirow{2}{*}{$\begin{array}{c}\text { Deskripsi Pekerjaan: } \\
\text { Tahap Pekerjaan }\end{array}$} & \multicolumn{5}{|c|}{$\begin{array}{l}\text { Pemasangan dinding beton pracetak bangunan Sektor } 1 \text { Gedung Apartemen Puncak } \\
\text { Bukit Golf Surabaya. }\end{array}$} \\
\hline & Potensi Bahaya & Likelihood & Severity & $\begin{array}{c}\text { Evaluasi Risiko } \\
\text { (Likelihood } \mathbf{x} \\
\text { Severity) }\end{array}$ & Kategori \\
\hline \multirow{2}{*}{$\begin{array}{l}\text { Pemasangan chain } \\
\text { block pada kolom } \\
\text { bangunan }\end{array}$} & Terjepit & 4 & 2 & 8 & Risiko sedang \\
\hline & Terjatuh dari ketinggian & 3 & 4 & 12 & Risiko tinggi \\
\hline \multirow{3}{*}{$\begin{array}{l}\text { Pemasangan sling } \\
\text { tower crane pada lift } \\
\text { hook beton pracetak }\end{array}$} & Terjepit & 4 & 2 & 8 & Risiko sedang \\
\hline & Tertimpa & 3 & 4 & 12 & Risiko tinggi \\
\hline & Tertabrak sling/ beton pracetak & 4 & 4 & 16 & Risiko tinggi \\
\hline \multirow{3}{*}{$\begin{array}{l}\text { Erection beton } \\
\text { pracetak }\end{array}$} & Beton pracetak terjatuh & 5 & 4 & 20 & Risiko tinggi \\
\hline & Tertabrak sling/ beton pracetak & 5 & 4 & 20 & Risiko tinggi \\
\hline & Terjatuh dari ketinggian & 5 & 4 & 20 & Risiko tinggi \\
\hline \multirow{4}{*}{$\begin{array}{l}\text { Pemindahan beton } \\
\text { pracetak dari sling } \\
\text { tower crane ke sling } \\
\text { chain block }\end{array}$} & Terjepit & 4 & 3 & 12 & Risiko tinggi \\
\hline & Terbentur & 4 & 3 & 12 & Risiko tinggi \\
\hline & Terjatuh dari ketinggian & 5 & 4 & 20 & Risiko tinggi \\
\hline & Beton pracetak terjatuh & 5 & 4 & 20 & Risiko tinggi \\
\hline \multirow{6}{*}{$\begin{array}{l}\text { Pengelasan beton } \\
\text { pracetak }\end{array}$} & Las terjatuh & 3 & 2 & 6 & Risiko sedang \\
\hline & Material terjatuh & 3 & 4 & 12 & Risiko tinggi \\
\hline & Terjatuh dari ketinggian & 5 & 4 & 20 & Risiko tinggi \\
\hline & Tersengat aliran listrik & 5 & 4 & 20 & Risiko tinggi \\
\hline & Gangguan penglihatan & 5 & 1 & 5 & Risiko rendah \\
\hline & Terkena percikan las & 5 & 2 & 10 & Risiko sedang \\
\hline \multirow{3}{*}{$\begin{array}{l}\text { Pelepasan sling } \\
\text { pengikat pracetak }\end{array}$} & Terjepit & 4 & 3 & 12 & Risiko tinggi \\
\hline & Terjatuh dari ketinggian & 5 & 4 & 20 & Risiko tinggi \\
\hline & Beton pracetak terjatuh & 5 & 4 & 20 & Risiko tinggi \\
\hline
\end{tabular}

dinding beton pracetak bangunan Apartemen Puncak Bukit Golf Surabaya ada beberapa tahapan pekerjaan yang dapat dikendalikan dengan metode eliminasi. Substitusi adalah teknik pengendalian bahaya dengan mengganti alat, bahan, sistem atau prosedur yang berbahaya dengan yang lebih aman atau lebih rendah bahayanya. Pengendalian teknis adalah pengendalian bahaya melalui perbaikan pada desain, penambahan peralatan dan pemasangan peralatan pengaman.

Dari hasil observasi, untuk mengendalikan risiko pada pemasangan dinding beton pracetak pengendalian teknis diterapkan dengan memasang besi pelindung pada tepian bangunan, memasang jaring pada tepi bangunan, dan kawat pelindung dari kejatuhan material. Pengendalian administratif adalah pengendalian bahaya yang dapat dilakukan secara administratif. Dari beberapa risiko yang teridentifikasi ada beberapa risiko yang dapat dikendalikan dengan metode pengendalian administratif, antara lain pekerja pemasang atau rigger dan operator tower crane yang harus memiliki Surat Perintah Kerja dari perusahaan. Perusahaan juga mengutamakan menggunakan pekerja yang sehat dan berpengalaman.

Terakhir ialah penggunaan alat pelindung diri (APD) merupakan langkah pengendalian yang terakhir oleh perusahaan apabila empat langkah sebelumnya sudah dilaksanakan. Langkah ini diantaranya ialah dengan memberikan alat pelindung diri (APD) kepada pekerja seperti sepatu safety, helmet, sarung tangan, kaca mata las, kacamata safety, dan safety belt.

Penilaian pengendalian risiko dilakukan berdasarkan pertimbangan penerapan pengendalian risiko yang ada di perusahaan, hasil wawancara dengan pekerja dan petugas $\mathrm{K} 3$ serta hasil observasi yang dilakukan pada aktivitas pekerjaan pemasangan dinding beton pracetak proyek pembangunan apartemen Puncak Bukit Golf Surabaya. 
Hasil penilaian pengendalian risiko pemasangan dinding beton pracetak adalah $57 \%$ potensi risiko dengan nilai pengendalian risiko $75 \%, 19 \%$ potensi risiko dengan nilai $65 \%, 19 \%$ potensi risiko dengan nilai $40 \%$, dan $5 \%$ potensi bahaya dengan pengendalian $25 \%$.

\section{Penilaian Risiko Sisa}

Perhitungan risiko sisa dapat dilakukan setelah melakukan penilaian risiko dan penilaian pengendalian risiko. Risiko sisa merupakan besarnya risiko akhir yang diterima setelah tindakan pengendalian diimplementasikan.

Hasil penghitungan risiko sisa menunjukkan beberapa potensi bahaya masih dalam kategori risiko tinggi. Dari hasil identifikasi potensi risiko awal didapat $62 \%$ potensi risiko tinggi, setelah dilakukan penilaian risiko sisa masih terdapat $19 \%$ risiko yang masuk dalam kategori risiko tinggi. Diantaranya ialah beton pracetak terjatuh pada tahapan pekerjaan erection beton pracetak, terjatuh dari ketinggian pada tahapan pekerjaan erection beton pracetak, terjatuh dari ketinggian pada tahapan pekerjaan Pemindahan beton pracetak dari sling tower crane ke sling chain block, dan terjatuh dari ketinggian pada tahapan pekerjaan pelepasan sling chain block. Dari hasil penghitungan risiko sisa juga didapat $38 \%$ kategori risiko sedang dan $43 \%$ kategori risiko rendah.

\section{PEMBAHASAN}

Berdasarkan hasil penelitian pada pekerjaan pemasangan dinding beton pracetak pada Proyek Pembangunan Apartemen Puncak Bukit Golf Surabaya bahwa pekerjaan pemasangan beton pracetak mempunyai 6 tahapan pekerjaan, yaitu: pemasangan chain block pada kolom bangunan, pemasangan sling tower crane pada lift hook beton pracetak, erection beton pracetak, pemindahan beton pracetak dari sling tower crane ke sling chain block, pengelasan beton pracetak, dan pelepasan chain block.

Masing-masing tahapan memiliki potensi risiko dan tahapan yang mempunyai potensi risiko dengan jumlah terbanyak yaitu tahapan pengelasan beton pracetak dengan 6 potensi risiko atau $29 \%$ dari seluruh potensi risiko pekerjaan pemasangan dinding beton pracetak. Sedangkan potensi risiko yang paling banyak muncul pada tiap tahapan pekerjaan adalah terjatuh dari ketinggian dengan jumlah 5 atau $24 \%$ dari seluruh potensi risiko pekerjaan pemasangan dinding beton pracetak.

Tabel 5. Penilaian Pengendalian Risiko dan Penilaian Risiko Sisa

\begin{tabular}{llccc}
\hline \multicolumn{1}{c}{ Langkah Kerja } & \multicolumn{1}{c}{ Potensi Bahaya } & Tingkat Risiko & Pengendalian Risiko & Risiko Sisa \\
\hline Pemasangan chain block & Terjepit & 8 & $75 \%$ & 2 \\
pada kolom bangunan & Terjatuh dari ketinggian & 12 & $65 \%$ & 4,3 \\
\hline Pemasangan sling tower & Terjepit & 8 & $75 \%$ & 2 \\
crane pada lift hook beton & Tertimpa & 12 & $65 \%$ & 4,2 \\
pracetak & Tertabrak sling/ beton pracetak & 16 & $75 \%$ & 12 \\
\hline Erection beton pracetak & Beton pracetak terjatuh & 20 & $40 \%$ & 7 \\
& Tertabrak sling/beton pracetak & 20 & $65 \%$ & 15 \\
\hline Pemindahan beton & Terjatuh dari ketinggian & 20 & $25 \%$ & 3 \\
pracetak dari sling tower & Terjepit & 12 & $75 \%$ & 3 \\
crane ke sling chain & Terbentur & 12 & $75 \%$ & 12 \\
block & Beton pracetak terjatuh & 20 & $40 \%$ & 5 \\
\hline Pengelasan beton & Las terjatuh & 20 & $75 \%$ & 3,6 \\
pracetak & Material terjatuh & 6 & $40 \%$ & 4,2 \\
& Terjatuh dari ketinggian & 12 & $65 \%$ & 5 \\
& Tersengat aliran listrik & 20 & $75 \%$ & 5 \\
& Gangguan penglihatan & 20 & $75 \%$ & 1,25 \\
Pelepasan sling pengikat & Terkena percikan las & 5 & $75 \%$ & 2,5 \\
\hline & Terjatuh dari ketinggian & 10 & $75 \%$ & 3 \\
\hline
\end{tabular}


Kategori risiko rendah gangguan penglihatan pada tahapan pekerjaan pengelasan beton pracetak, likelihood sering terjadi dan severity sangat ringan sehingga dikategorikan risiko rendah. Selain itu juga pekerja sudah dilengkapi penutup muka dan kacamata dengan filter khusus (Anizar, 2009).

Beberapa potensi bahaya yang termasuk risiko sedang adalah terjepit pada pemasangan chain block pada kolom bangunan dan pada pemasangan sling tower crane pada lift hook beton pracetak dengan likelihood kategori sering dan severity ringan, sehingga risiko sedang. Pengendalian untuk risiko terjepit ialah dengan pemakaian alat pelindung diri berupa penggunaan sepatu steel box toe dan sarung tangan kulit berlengan panjang (Anizar, 2009).

Las terjatuh pada pekerjaan pengelasan beton pracetak dengan likelihood mungkin terjadi dan severity luka ringan, sehingga dikategorikan risiko sedang. Pengendalian risiko pada risiko las terjatuh ialah dengan pemasangan jaring pada tepi bangunan, penggunaan sarung tangan asbes, penggunaan sepatu safety steel box toe (Anizar, 2009).

Terkena percikan las pada pekerjaan pengelasan beton pracetak dengan likelihood pasti terjadi dan severity luka ringan, sehingga dikategorikan risiko sedang. Pengendalian risiko pada risiko terkena percikan las adalah penggunaan googles, penutup muka, kacamata dengan filter khusus, jaket tahan api (asbes) atau kulit, dan sepatu yang dilapisi baja (Anizar, 2009).

Potensi bahaya yang termasuk risiko tinggi meliputi terjatuh dari ketinggian pada tahap pekerjaan pemasangan chain block pada kolom bangunan yang mempunyai likelihood mungkin terjadi dan severity parah sehingga dikategorikan risiko tinggi. Pengendalian risiko pada potensi terjatuh dari ketinggian ialah membersihkan lingkungan kerja, menjaga lantai agar tidak licin, memberikan training mengenai posisi kerja, memperhatikan faktor cuaca, dan penggunaan safety shoes ter-standard (Tambunan, 2007).

Tertimpa pada tahapan pekerjaan pemasangan sling tower crane pada lift hook beton pracetak dengan likelihood mungkin terjadi dan severity kecelakaan berat sehingga dikategorikan dalam kategori risiko tinggi. Pengendalian risiko tertimpa adalah dengan penggunaan helm pengaman dengan kriteria bagian kulit pelindung atau cangkang harus memiliki kemampuan untuk menyerap sebagian besar gaya atau guncangan akibat benturan benda jatuh, bagian kulit atau cangkang tidak bisa ditembus atau dirobek oleh benda jatuh, harus memiliki kemampuan insulasi terhadap bahaya listrik, tahan api, tahan air, dan bisa diatur penggunaannya sesuai dengan kebutuhan atau ukuran kepala pengguna (Tambunan, 2007).

Tertabrak sling/beton pracetak pada tahapan pekerjaan pemasangan sling tower crane pada lift hook beton pracetak yang memiliki likelihood sering terjadi dan severity kecelakaan berat sehingga dikategorikan risiko tinggi. Pengendalian risiko tertabrak sling/beton pracetak adalah dengan memberikan training pada rigger dan operator tower crane, penggunaan handy talky untuk memudahkan komunikasi antara rigger dan operator tower crane, dan penggunaan APD berupa safety helmet, sepatu safety, jaket atau jas kulit, kacamata yang menutupi seluruh samping mata, tameng plastik pelindung muka, dan sarung tangan kulit (Anizar, 2009).

Beton pracetak terjatuh pada tahapan pekerjaan erection beton pracetak dengan likelihood pasti terjadi dan severity berat sehingga dikategorikan risiko tinggi. Pengendalian risiko dengan memberikan pelatihan pada rigger, safety induction, dan penggunaan sarung tangan dari kulit (Anizar, 2009).

Tertabrak beton pracetak pada tahapan pekerjaan erection beton pracetak dengan likelihood pasti terjadi dan severity berat sehingga dikategorikan risiko tinggi. Pengendalian risiko tertabrak sling/ beton pracetak adalah dengan memberikan training pada rigger dan operator tower crane, penggunaan handy talky untuk memudahkan komunikasi antara rigger dan operator tower crane, dan penggunaan APD berupa safety helmet, sepatu safety, jaket atau jas kulit, kacamata yang menutupi seluruh samping mata, tameng plastik pelindung muka, dan sarung tangan kulit (Anizar, 2009).

Terjatuh dari ketinggian pada tahap pekerjaan erection beton pracetak yang mempunyai likelihood pasti terjadi dan severity berat sehingga dikategorikan risiko tinggi. Pengendalian risiko pada potensi terjatuh dari ketinggian ialah membersihkan lingkungan kerja, menjaga lantai agar tidak licin, memberikan training mengenai posisi kerja, memperhatikan faktor cuaca, dan penggunaan safety shoes ter-standard (Tambunan, 2007).

Terjepit pada tahapan pekerjaan pemindahan beton pracetak dari sling tower crane ke chain block dengan likelihood sering dan severity sedang sehingga dikategorikan risiko tinggi. Pengendalian risiko pada risiko terjepit adalah dengan penggunaan alat pelindung diri berupa 
sarung tangan kulit, dilapisi logam, dan berlengan panjang (Anizar, 2009).

Terbentur pada tahapan pekerjaan pemindahan beton pracetak dari sling tower crane ke sling chain block dengan likelihood sering dan severity sedang sehingga dikategorikan risiko tinggi. Pengendalian risiko pada risiko terbentur adalah dengan pengendalian administratif dan penggunaan helm yang terbuat dari material logam atau plastik (Anizar, 2009).

Terjatuh dari ketinggian pada tahapan pekerjaan pemindahan beton pracetak dari sling tower crane ke sling chain block dengan likelihood pasti terjadi dan severity berat sehingga dikategorikan risiko tinggi. Pengendalian risiko pada potensi terjatuh dari ketinggian ialah membersihkan lingkungan kerja atau pelaksanaan housekeeping yang baik, menjaga lantai agar tidak licin, memberikan training mengenai posisi kerja, memperhatikan faktor cuaca, dan penggunaan safety shoes ter-standard (Tambunan, 2007).

Beton pracetak terjatuh pada tahapan pekerjaan pemindahan beton pracetak dari sling tower crane ke sling chain block dengan likelihood pasti terjadi dan severity berat sehingga dikategorikan risiko tinggi. Pengendalian risiko dengan memberikan pelatihan pada rigger dan operator tower crane, safety induction, dan penggunaan sarung tangan dari kulit (Anizar, 2009).

Material terjatuh pada tahapan pekerjaan pengelasan beton pracetak dengan likelihood mungkin terjadi dan severity berat sehingga dikategorikan risiko tinggi. Pengendalian risiko material terjatuh adalah dengan pengendalian administratif dengan memberi pelatihan pada rigger dan operator tower crane, pemeriksaan kesehatan pekerja secara berkala, pelaksanaan housekeeping yang baik, memberi jaring pelindung pada tepi bangunan, dan memberi kewajiban pada penggunaan alat pelindung diri bagi pekerja berupa helm, sepatu safety (Anizar, 2009).

Terjatuh dari ketinggian pada tahapan pekerjaan pengelasan beton pracetak dengan likelihood pasti terjadi dan severity berat sehingga dikategorikan risiko tinggi. Pengendalian risiko pada potensi terjatuh dari ketinggian ialah bangunan diberi pagar pelindung (guard rails), pagar pelindung tengah (intermediate rails), pijakan kaki (toe boards) setinggi 6 inci, dan tali-temali atau jaring pengaman (Ridley, 2004).
Tersengat aliran listrik pada tahapan pekerjaan pengelasan beton pracetak dengan likelihood pasti terjadi dan severity berat sehingga dikategorikan risiko tinggi. Pengendalian tersengat aliran listrik saat pengelasan adalah dengan pengendalian administratif, pelaksanaan housekeeping yang baik, dan penggunaan alat pelindung diri berupa sarung tangan asbes berlengan panjang, sepatu safety, dan jaket asbes atau kulit (Anizar, 2009).

Terjepit pada tahapan pekerjaan pelepasan sling pengikat pracetak dengan likelihood sering terjadi dan severity sedang sehingga dikategorikan risiko tinggi. Pengendalian risiko pada risiko terjepit adalah dengan penggunaan alat pelindung diri berupa sarung tangan kulit (Anizar, 2009).

Terjatuh dari ketinggian pada tahapan pekerjaan pelepasan sling pengikat pracetak dengan likelihood pasti terjatuh dan severity berat sehingga dikategorikan risiko tinggi. Pengendalian risiko pada potensi terjatuh dari ketinggian ialah membersihkan lingkungan kerja, menjaga lantai agar tidak licin, memberikan training mengenai posisi kerja, memperhatikan faktor cuaca, dan penggunaan safety shoes ter-standard (Tambunan, 2007).

Beton pracetak terjatuh pada tahapan pekerjaan pelepasan sling pengikat pracetak dengan likelihood pasti terjadi dan severity berat sehingga dikategorikan risiko tinggi. Pengendalian risiko dengan memberikan pelatihan pada rigger, safety induction, dan penggunaan sarung tangan dari kulit (Anizar, 2009).

Risiko jatuh dari ketinggian termasuk kategori risiko tinggi karena dilihat dari severity yang menyebabkan kehilangan nyawa seseorang. Tindakan atau response yang disarankan pada tingkat risiko tinggi ialah harus dilakukan intervensi atau pengendalian untuk perbaikan, sampai pada tingkat risiko yang dapat diterima (acceptable risk) atau dihilangkan kalau memungkinkan (Kurnawidjaya, 2010).

Potensi risiko bisa dikendalikan guna mencegah kecelakaan kerja dengan pengendalian risiko sebagai berikut: eliminasi, substitusi, pengendalian teknis, pengendalian administratif, dan penggunaan alat pelindung diri (Ramli, 2010).

Dari penghitungan risiko sisa didapat $19 \%$ risiko yang masih dalam kategori risiko tinggi. Penanganan risiko tidak mungkin menjamin risiko atau bahaya hilang seratus persen, sehingga masih ada risiko sisa yang perlu dipertimbangkan oleh perusahaan (Ramli, 2010). 


\section{SIMPULAN}

Potensi bahaya yang teridentifikasi pada pekerjaan pemasangan dinding beton pracetak pada proyek pembangunan apartemen Puncak Bukit Golf adalah: terjatuh dari ketinggian, terjepit, tertimpa, tertabrak sling/beton pracetak, material terjatuh, tersengat listrik, terbentur, las terjatuh, gangguan penglihatan, terkena percikan las, dan tertimpa.

Penilaian risiko awal pada pekerjaan pemasangan dinding beton pracetak proyek pembangunan apartemen Puncak Bukit Golf didapatkan $76 \%$ risiko tinggi, $19 \%$ risiko sedang, dan $5 \%$ risiko rendah.

Pengendalian risiko yang telah dilakukan pada pekerjaan pemasangan dinding beton pracetak Proyek Pembangunan Apartemen Puncak Bukit Golf meliputi: pengendalian secara teknik dengan pemasangan pagar dan jaring agar pekerja dan material tidak jatuh ke bawah. Pengendalian secara administratif meliputi instruksi kerja, safety induction, pemeriksaan komponen dan peralatan, dan memastikan pekerja sudah berpengalaman dan sehat. Pengendalian dengan APD (alat pelindung diri) meliputi penggunaan helm safety, sepatu safety, kacamata las, kacamata safety, jaket kulit, dan sarung tangan.

Dari hasil perhitungan risiko sisa didapat 19\% potensi risiko sisa yang masih dalam kategori tinggi dan potensi bahaya terjatuh dari ketinggian pada tahapan pekerjaan erection dinding beton pracetak adalah yang tertinggi dengan nilai risiko 15 .

\section{DAFTAR PUSTAKA}

Anizar. 2009. Teknik Keselamatan dan Kesehatan Kerja di Industri. Yogyakarta: Graha Ilmu.

Harianto, F. 2014 Analisis Risiko Keselamatan dan Kesehatan Kerja (K3) pada Proyek Pembangunan Apartemen Educity Residence Pakuwon City Surabaya. Surabaya: ITATS.

Kurnawidjaya, M. 2010. Konsep Dasar Kesehatan Kerja. Jakarta: UI Press.

PT. Freeport Indonesia. 2008. Risk Assessment. Martapura.

Ridwan, M. 2010. "Kecelakaan Kerja Terbanyak di Sektor Konstruksi" www.jamsostek.co.id 15 Januari 2010.

Ridley, J. 2004. Kesehatan dan Keselamatan Kerja. Jakarta: Penerbit Erlangga.

Siswanto, A. 2009. Risk Assessment. Surabaya.

Suardi, R. 2007. Sistem Manajemen Keselamatan dan Kesehatan Kerja. Jakarta: CV Agung Seto.

Suma'mur. 2009. Higiene Perusahaan dan Kesehatan Kerja (HIPERKES). Jakarta: Sagung Seto.

Tambunan, T. 2007. Personal Protective Equipment. Yogyakarta: Graha Ilmu.

Tjitrosoma, R. 2012. Perancangan Modifikasi Struktur Gedung RSUD. Dr. Kanujoso Djatiwibowo Menggunakan Beton Pracetak (Precast) dan Metode Pelaksanaan. Surabaya: Institut Teknologi Sepuluh November. 